\title{
Protetores de analitos e efeito de matriz em GC
}

\author{
Lara Cristina Teixeira Soares ${ }^{1}$, Álvaro José dos Santos-Neto ${ }^{2 *}$ \\ ${ }^{1}$ Instituto de Química, Universidade Federal de Alfenas - UNIFAL, Rua Gabriel Monteiro da Silva, 700, \\ Cep 37130-000, Alfenas, MG, Brasil \\ ${ }^{2}$ Instituto de Química de São Carlos, Universidade de São Paulo - USP, Av. Trabalhador São-carlense, 400, \\ Cep 13560-970, São Carlos, SP, Brasil \\ e-mail: alvarojsn@iqsc.usp.br
}

\section{Resumo}

Muito se fala atualmente a respeito dos efeitos deletérios provocados por interferentes remanescentes da matriz da amostra em cromatografia líquida acoplada à espectrometria de massas. Todavia, a ocorrência de problemas relacionados a efeitos de matriz não é exclusiva da técnica acima, atingindo também a bastante tradicional cromatografia em fase gasosa. Tanto na cromatografia líquida de alta eficiência quanto na gasosa, os problemas têm uma origem comum: a existência de interferentes provenientes da matriz no extrato a ser analisado. Contudo, suas consequências são essencialmente diferentes em relação aos tipos de problemas provocados. Particularmente para a cromatografia gasosa, os problemas não predominam no seu acoplamento à espectrometria de massas, podendo ser observados praticamente com todos os outros detectores, e sendo inerentes ou intrínsecos à técnica cromatográfica propriamente dita. Nesse artigo, será feita uma discussão sucinta, porém abrangente, acerca dos efeitos que a matriz exerce sobre a técnica de cromatografia gasosa. Ademais, será discutido, em particular, o papel que se tem atribuído aos chamados "protetores de analito". Estes últimos são usados na tentativa de mitigar os efeitos negativos que a matriz exerce na aplicação dos métodos em situações reais; sem, entretanto, desconsiderar os efeitos favoráveis à técnica, conferidos pelos remanescentes da matriz no extrato final.

Palavras-chave

GC; cromatografia gasosa; efeito de matriz; protetores de analito; troubleshooting; praguicidas.

\section{Analyte protectants and matrix effects in $\mathrm{GC}$}

\section{Abstract}

Special attention has been paid about the deleterious effects caused by interferences from the sample matrix in liquid chromatography coupled to mass spectrometry. However, the occurrence of problems related to matrix effects is not exclusive from the above technique, also reaching the very traditional gas chromatography. In both cases, gas chromatography and high performance liquid chromatography, the problems have a common origin, the existence of matrix interferences from the extract to be analyzed. Nevertheless, its consequences are essentially different in the types of problems arising. Particularly for gas chromatography, problems are not regarded exclusively with its coupling to mass spectrometry, actually they can be observed with virtually all other detectors and being intrinsic or inherent to the 
chromatographic technique itself. In this article a brief but comprehensive discussion will be conducted about the effects that the matrix exerts on the gas chromatography. Furthermore, it will be discussed, in particular, the role that has been allocated for the so-called "analyte protectants". These compounds are used in an attempt to mitigate the negative effects that the matrix plays in the application of methods in real situations; without, however, dismiss the favorable effects to the technique, conferred by the remaining compounds of the matrix in the final extract.

Keywords

GC; gas chromatography; matrix effect; analyte protectants; troubleshooting; pesticides.

\section{Aspectos gerais do efeito de matriz}

Implicações do efeito de matriz sobre a cromatografia são reconhecidas há muito tempo, podendo esse efeito ser indesejado ou explorado positivamente $^{[1,2]}$. Na atualidade, um dos principais focos de atenção sobre o efeito de matriz dá-se com o acoplamento cromatografia líquida-espectrometria de massas (LC-MS) ${ }^{[3]}$.

Em LC-MS, geralmente o efeito de matriz é altamente indesejável sendo combatido principalmente por meio de esforços no preparo da amostra e na separação cromatográfica ${ }^{[4,5]}$. Basicamente, a presença de interferentes da matriz, eluindo em tempos de retenção próximos àqueles dos analitos, leva a perturbações no processo de obtenção dos respectivos íons a serem analisados no espectrômetro de massas. Podem ocorrer problemas de supressão ou aumento da ionização dos analitos, levando a problemas, entre outros, na quantificação desses compostos. A técnica de ionização por electrospray (ESI) costuma ser a mais afetada pelo efeito de matriz, mas há casos em que a ionização química à pressão atmosférica (APCI) pode ser, até mesmo, mais prejudicada do que a $\mathrm{ESI}^{[4]}$.

Como um fenômeno a ser combatido em LC-MS, todos os esforços direcionam-se para a sua completa eliminação, ou, ao menos, para a sua redução a níveis aceitáveis e controlados. Por outro lado, o efeito de matriz em cromatografia gasosa (GC) apresenta alguns contrastes em relação ao que ocorre em cromatografia líquida de alta eficiência (HPLC).

Esse artigo dedica-se a apresentar as características do efeito de matriz sobre a cromatografia gasosa. Em particular, será dada atenção ao uso dos compostos denominados como "protetores de analito". Esses tópicos são relevantes em situações de aplicação da técnica em análises envolvendo matrizes complexas, como tem sido muito comum atualmente no caso da determinação de praguicidas em alimentos em geral, mas que podem ser ampliados a fármacos e drogas em matrizes biológicas e a combustíveis, entre outros.

\section{O efeito de matriz em cromatografia gasosa}

Conforme mencionado anteriormente, a cromatografia gasosa tem comportamento diferenciado frente à existência do efeito de matriz, em relação à HPLC. Primeiramente, em alguns casos, esse fenômeno pode ser explorado positivamente, melhorando o desempenho da técnica 
de separação (precisão, exatidão e detectabilidade, entre outros). Adicionalmente, a sua ocorrência não se restringe a afetar apenas a detecção baseada em espectrometria de massas (MS), visto que age, também, intrinsecamente sobre o processo cromatográfico. Apesar de o efeito ser mais predominante e evidente no acoplamento GC-MS, outros modos de detecção podem ser $\operatorname{afetados}^{[6]}$.

Essa tendência mais ubíqua do efeito de matriz em GC deve-se a esses efeitos exercerem ações desde o ponto de injeção até o detector do instrumento. Conforme abordado na revisão de Pinho e colaboradores ${ }^{[6]}$, detectores mais sensíveis tornam esse efeito mais evidente, como ocorre em uma comparação entre a detecção por captura de elétrons (ECD) e usando o detector de nitrogênio-fósforo (NPD), em que o primeiro é mais afetado. As características físicas do detector também interagem com o efeito de matriz, implicando em maior ou menor evidência aos problemas. Por exemplo, o espectrômetro de massas, com superfícies metálicas expostas aos analitos e interferentes, sofre mais do que detectores que utilizam combustão imediatamente após a coluna, como no caso da detecção fotométrica em chama (FPD).

Retomando o assunto de sua origem, a explicação mais aceita para o efeito de matriz em GC foi fornecida por Erney e colaboradores em $1993^{[7]}$. Acredita-se que o mascaramento dos sítios ativos ao longo do sistema de GC pelos constituintes da amostra seja o principal mecanismo que leva ao aparecimento do efeito de matriz. Esse efeito costuma ser observado pelo aumento na intensidade e melhoria no formato dos picos dos analitos, quando injetados sob a presença de matriz. Por outro lado, quando a matriz está ausente, picos menos intensos e, eventualmente, deformados, são observados para os analitos susceptíveis. Enfim, a presença da matriz faz com que menor número de sítios ativos esteja disponível para interagir com esses analitos, resultando em menos perdas e em melhores formatos para os picos. A Figura 1 ilustra esse processo, exemplificando com o que se acredita que ocorra no interior do injetor do cromatógrafo, no qual os analitos podem encontrar sítios ativos no glass insert e em seu recheio (lã de vidro ou outro material de preenchimento que pode ser usado em seu interior).

Da mesma forma como mostrado para o injetor, interações com sítios ativos também podem ocorrer ao longo da coluna cromatográfica e, em alguns casos, no detector. De fato, cada ponto de conexão no caminho dos analitos, potencialmente, pode exercer tal efeito, conforme já foi reportado ${ }^{[6]}$.
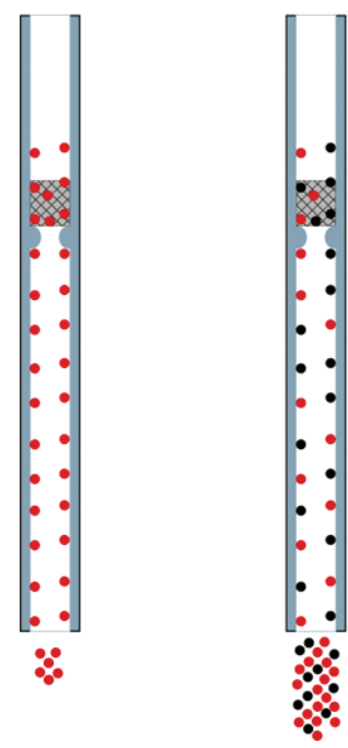

Analiticos

Componentes

da matriz

Lã de vidro

Figura 1 Esquema em corte do local de inserção da amostra (glass insert) no injetor de um cromatógrafo a gás. (A) Representação da sorção indesejada dos analitos em sítios ativos quando amostra isenta de componentes da matriz é injetada. (B) Representação de uma maior transferência dos analitos, provocada pela ocupação dos sítios ativos por componentes da matriz, no caso de amostra que os contenha. 
Vários fatores estão envolvidos no efeito do mascaramento induzidos pela matriz. Obviamente, o número e as características dos sítios ativos do sistema de GC são imprescindíveis a esse efeito. As propriedades dos analitos também são relevantes, de maneira que estruturas químicas que favoreçam ligações de hidrogênio, ou mesmo a termolabilidade dos compostos delineiam os compostos mais afeitos a sofrer esses efeitos. A própria concentração dos analitos é fator influente, o que, por si, leva a problemas de quantificação. Nesse caso, em geral, baixas concentrações dos analitos sofrem mais com a presença dos sítios ativos. De maneira análoga, proporções pequenas entre os analitos e os concomitantes da matriz também resultam nos mesmos efeitos. Outro fator que pode ser citado relaciona-se ao tipo de matriz e a sua concentração. Por fim, as condições empregadas no método de análise são importantes. A temperatura de injeção exerce uma ação importante e direta na transferência dos analitos para fora do injetor. Além dela, outros parâmetros que definem o tempo de permanência no injetor são a vazão do gás de arraste, o uso de pulsos de pressão, o volume de injeção, o volume de expansão do solvente, o diâmetro da coluna e o tempo de retenção dos analitos. Maiores detalhes sobre as características de cada um desses fatores podem ser consultadas nos trabalhos de Anastassiades et al. ${ }^{[8]}$ e Pinho et al. ${ }^{[6]}$.

Em suma, o efeito de matriz em GC resulta em variações na intensidade e formato dos picos cromatográficos dos analitos susceptíveis. Dessa forma, a sua principal implicação é afetar o aspecto quantitativo das análises. É sabido que existem diversas formas de calibração (padronização externa ou interna, adições de padrão, compatibilização da matriz (matrix-matched)), e cada qual lida de uma maneira diferente com a influência exercida pela matriz. Além disso, os protocolos preconizados e aceitos por diferentes agências e órgãos reguladores, de diferentes setores e países, divergem nos métodos aceitos para calibração, validação e aplicação das metodologias.

De modo geral, a calibração mais simples é aquela que utiliza a padronização externa. Porém é uma das que mais sofre com o efeito de matriz. Enquanto alguns protocolos não aceitam ou indicam essa opção, outros a deixam como única opção viável.

A padronização interna, particularmente no caso do uso de padrões isotópicos em espectrometria de massas, tem grande êxito na correção do efeito de matriz. Por outro lado, é de aplicação limitada, quer seja pela indisponibilidade ou custo excessivo dos padrões necessários. A padronização interna com compostos análogos, por usa vez, já não possui as mesmas chances de sucesso da opção com padrões isotópicos e deve ser avaliada isoladamente para cada composto de interesse.

O método das adições de padrão é um dos mais indicados para corrigir o efeito de matriz, todavia é moroso por exigir diversas análises para a mesma amostra. Assim, muitas vezes, a aplicação em situações reais, com grande número de amostras, é inviabilizada. Ademais, dependendo do tipo do efeito exercido pela matriz, não há compensação, sendo dependente, ainda, de métodos auxiliares ${ }^{[9]}$.

Por fim, o método de compatibilização da matriz (matrix-matched) também é bastante adequado para a compensação dos efeitos de matriz. Por sua vez, ele exige que haja exemplares compatíveis de matriz isenta dos analitos (bran$\cos )$, requisito que nem sempre é preenchido. Ademais, alguns protocolos não aceitam sua utilização. 

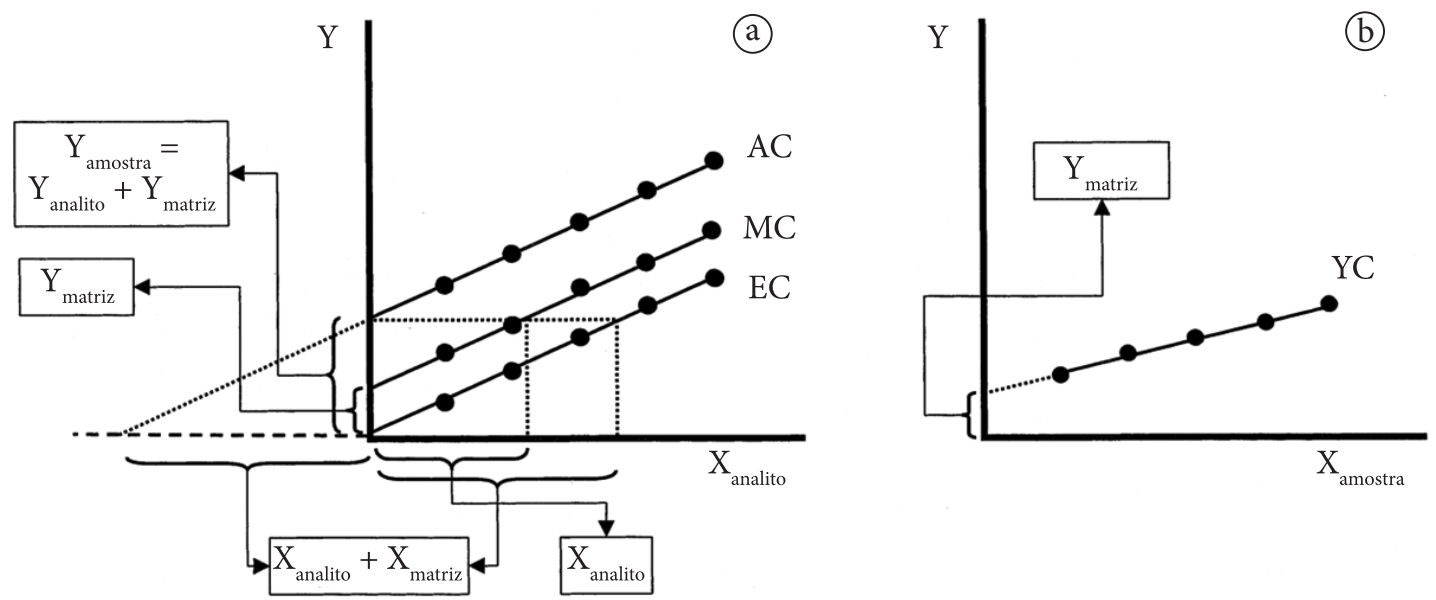

Figura 2 Inter-relação entre diferentes tipos de curvas de calibração. (a) Calibração com padronização externa (EC), calibração com compatibilização da matriz (matrix-matched) (MC) e calibração por adições de padrão (AC). (b) "Calibração" com a amostra ou "Calibração" de Youden (YC). $\mathbf{Y}_{\text {amostra' }^{\prime}}$ sinal da amostra; $\mathbf{Y}_{\text {matriz' }^{\prime}}$ sinal da matriz branca; $\mathbf{Y}_{\text {analito' }}$ sinal real do analito na amostra; $\mathbf{x}_{\text {analito' }}$ concentração real do analito na amostra; $\mathbf{x}_{\text {matriz' }}$ incerteza aditiva causada pela matriz. Com permissão, a partir da referência 9 .

A revisão de Cuadros-Rodríguez e colaboradores $^{[9]}$ descreve e ilustra com figuras cada uma das situações de calibração e pode ser interessante para a revisão sobre os conceitos de calibração descritos acima. A Figura 2, adaptada dessa referência, ilustra as diferenças entre cada calibração em relação às contribuições da matriz.

Essa breve descrição sobre calibração é relevante para entender-se que o efeito de matriz pode atuar de maneira diferente, a depender do método de calibração utilizado. Particularmente no caso da GC, esse efeito em questão costuma levar a superestimações da concentração do analito, quando o método é calibrado sem sofrer a mesma influência da matriz em relação àquela presente na amostra real.

De qualquer maneira, muitas vezes, buscam-se formas de mitigar esse efeito de matriz, ou, até mesmo, formas mais adequadas para lidar-se com ele. Obviamente, as calibrações por adições de padrão, o uso de padrões isotópicos (surrogates, deuterados ou com carbono-13) e a compatibilização de matriz (matrix-matched) já se incluem nesse rol. Adicionalmente, pode-se citar o extensivo preparo da amostra, com o objetivo de uma suficiente limpeza dos interferentes que provocam o efeito de matriz. Alguns métodos de injeção em GC também são explorados para reduzir o efeito da matriz. Por exemplo, a injeção em coluna fria (cold on-column injection) é uma forma descrita na literatura, a qual, contudo, nem sempre é viável com o tipo de instrumentação disponível no laboratório. Por sua vez, alguns sistemas de GC permitem a injeção associada a um pulso de pressão, ao qual se atribui uma melhor e mais rápida transferência dos analitos para a coluna cromatográfica, também sendo uma opção para tentar-se reduzir o efeito da matriz. Alguns métodos, adicionalmente, sugerem um pré-condicionamento do injetor, com injeções prévias de matriz, com o intuito de saturá-lo ${ }^{[7]}$. Por fim, existem protocolos que buscam estabelecer uma função matemática que consiste em um fator corretivo para as diferenças 
entre a amostra real e os calibradores. As diferentes formas de se lidar com o efeito de matriz são discutidas na revisão de Pinho et al. ${ }^{[6]}$, previamente apresentada.

Além das possibilidades listadas no parágrafo anterior, o uso dos "protetores de analito" tem merecido atenção. O seu uso é interessante, pois, como mencionado anteriormente, algumas vezes os efeitos provocados pela matriz em GC favorecem a análise em geral. Como visto, o mascaramento dos sítios ativos pela matriz costuma levar à melhoria no formato e intensidade dos picos de compostos que sofrem com essas interações indesejadas.

A grande quantidade de constituintes da matriz, por outro lado, pode levar a problemas na análise cromatográfica, ou, eventualmente, a uma maior frequência nos procedimentos de manutenção e limpeza do sistema. Dessa forma, cada vez mais são desenvolvidos e usados métodos de preparo de amostras que permitam boa limpeza da amostra, minimizando a presença de seus constituintes no extrato final a ser analisado no GC.

Enquanto, por um lado, uma boa limpeza da matriz é desejada e traz vantagens, por outro, compostos com potencial para mascarar os sítios ativos podem também ser removidos dessa matriz, piorando o perfil cromatográfico final. Dentro desse contexto, a adição deliberada de compostos selecionados, ao extrato a ser injetado no sistema cromatográfico, pode trazer uma série de vantagens e características positivas à análise. São justamente esses compostos os denominados "protetores de analito", os quais agem, de maneira análoga a alguns constituintes da matriz, mascarando a interação indesejada e descontrolada dos analitos com os sítios ativos do sistema cromatográfico.

\section{Protetores de analitos}

A primeira tentativa de uso de substâncias com o intuito de proteger os analitos de uma perda ou destruição no sistema cromatográfico é atribuída a Erney e Poole, ainda em 1993 ${ }^{[10]}$. Todavia, somente dez anos depois, em um estudo mais abrangente, avaliando 93 diferentes compostos, Anastassiades e colaboradores ${ }^{[8]}$ obtiveram sucesso e demonstraram benefícios para o uso das substâncias as quais eles denominaram "protetores de analito".

$\mathrm{O}$ uso desses protetores, de fato, coincide com a introdução da metodologia denominada de "QuEChERS", tendo sido reportada no seu artigo original ${ }^{[11]}$. Nesse trabalho, observa-se que o uso do sorvente amina primária secundária (primary secondary amine, PSA) é capaz de remover interferentes polares da matriz, porém, ao mesmo tempo, essa remoção leva à piora no comportamento cromatográfico. Diante dessa situação, o uso de protetores de analitos é desejado, conforme foi demonstrado e será mais discutido a seguir.

Os benefícios dos protetores de analitos, em relação às alternativas apresentadas na seção anterior incluem: (a) ser um procedimento simples; (b) melhorar a integração dos picos; (c) diminuir os limites de detecção; (d) melhorar a quantificação; (e) reduzir custos; e (f) reduzir a manutenção do injetor do GC. Este último benefício deve ser compreendido, em contrapartida à opção de injetar-se um extrato de amostra menos purificado em relação aos constituintes da matriz (ou seja, sujeito a um preparo de amostras menos efetivo na limpeza do extrato).

O procedimento é simples, pois se trata apenas da adição de um pequeno volume de solução ao extrato a ser injetado, o qual contém um ou mais protetores em concentração pré-estabelecida. Conforme é ilustrado na Figura 3, o uso de 


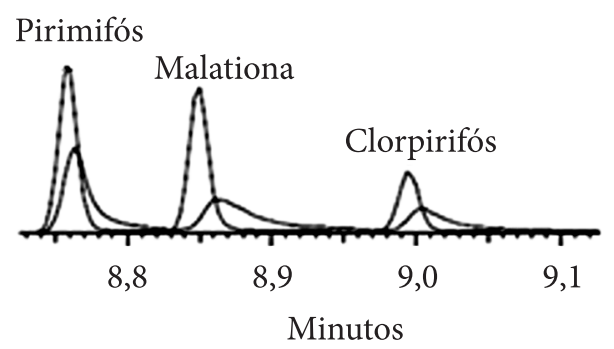

Figura 3 Comparação dos cromatogramas obtidos na presença e ausência de cafeína ( $1,0 \mathrm{mg} / \mathrm{mL})$ como agente protetor de analito. Extrato proveniente da utilização de metodologia baseada em QuEChERS para a análise de praguicidas em café torrado.

um protetor de analito melhorou o perfil cromatográfico obtido após o processamento de uma amostra complexa, usando metodologia baseada em QuEChERS. Obviamente a melhora na intensidade do sinal e na simetria dos picos implica nos benefícios b e c, listados anteriormente. Os aspectos quantitativos podem ser atribuídos a melhorias na precisão e exatidão, as quais serão ilustradas adiante. Por ser um procedimento simples, rápido e compatível ao preparo de amostras por QuEChERS, trás consigo as vantagens de custo reduzido. Por fim, a redução em custos também está relacionada à menor manutenção, ao se garantir maior tempo de uso do sistema entre os intervalos para limpeza/manutenção.

Atribuem-se os ganhos com o uso dos protetores de analito a quatro fatores: (1) estabilização dos analitos na solução do extrato; (2) completa transferência dos analitos do injetor/ vaporizador para a coluna; (3) minimização da distorção e difusão do analito em sua focalização no início da coluna e em sua separação ao longo dela; (4) eliminação da assimetria dos picos causada por interações fortes com a fase estacionária. Observa-se ainda que esses fatores incidem isoladamente ou cumulativamente sobre os analitos em particular, a depender de suas características. Na discussão desses aspectos, o trabalho de Anastassiades et al. ${ }^{[8]}$ é bastante informativo e completo, propondo mecanismos para a ação protetora dos compostos avaliados.

A ação estabilizante em solução pode ser exemplificada pelo papel de alguns ácidos, os quais previnem a perda de praguicidas sensíveis à degradação em meio alcalino. De fato, para alguns praguicidas, o uso de ácido acético como aditivo previne uma ampla e rápida degradação no extrato obtido e, até mesmo, durante a etapa prévia de preparo da amostra. A questão da melhor transferência dos analitos para a coluna já foi bem ilustrada na Figura 1, demonstrando-se que o mascaramento dos sítios ativos do injetor/ vaporizador contribui para reduzir as perdas por adsorção irreversível e até mesmo a degradação dos analitos. O terceiro fator pode ser atribuído à menor difusão do analito na fase estacionária e no gás de arraste, devido a sua coeluição com os protetores que se encontram em concentração bem mais alta. Por fim, a minimização das caudas dos picos pode ser relacionada ao mascaramento dos sítios ativos ao longo da coluna, por exemplo, pela coeluição de compostos que bloqueiem os grupos silanóis.

A escolha do melhor agente protetor de analito depende dos compostos a serem analisados. Primeiramente, é importante observar a existência de analitos que têm um bom comportamento em GC e, independentemente de estarem ou não expostos a um efeito de matriz, apresentarão uma resposta relativamente estável, dispensando-se o uso de protetores. Como mencionado, mais de 90 compostos foram avaliados no trabalho pioneiro de Anastassiades et al. ${ }^{[8]}$, entre eles, açúcares e seus derivados (alcoóis, lactonas), dióis, poliéteres, e alguns compostos básicos. Apesar de atentarem para o risco de uma indesejada "caramelização" no interior do cromatógrafo, foi demonstrado que alguns açúcares e derivados lactonas apresentaram bons resultados para 
vários praguicidas. De acordo com a diversidade de analitos a serem analisados, a combinação de agentes protetores pode ser interessante, conforme demonstrado em trabalho posterior do mesmo grupo, associando-se etilglicerol, gulonolactona e sorbitol ${ }^{[12]}$. De acordo com experiência própria, a associação entre PEG 300 e cafeína também mostrou-se atrativa para alguns praguicidas organofosforados ${ }^{[13]}$.

A escolha dos protetores de analito é empírica, de maneira que eles devem ser triados frente aos analitos de interesse que forem susceptíveis a efeitos de matriz. A Figura 4 ilustra o efeito de diferentes protetores sobre o praguicida ometoato, em que se observa um desempenho bastante diversificado para os protetores avaliados. Além da escolha dos tipos de protetores adequados para cada analito e método de análise, a concentração ideal deve ser estudada. A Figura 5 ilustra o efeito da concentração de apenas um protetor sobre apenas um analito. Porém, deve-se ressaltar que, nos casos de combinações de protetores,

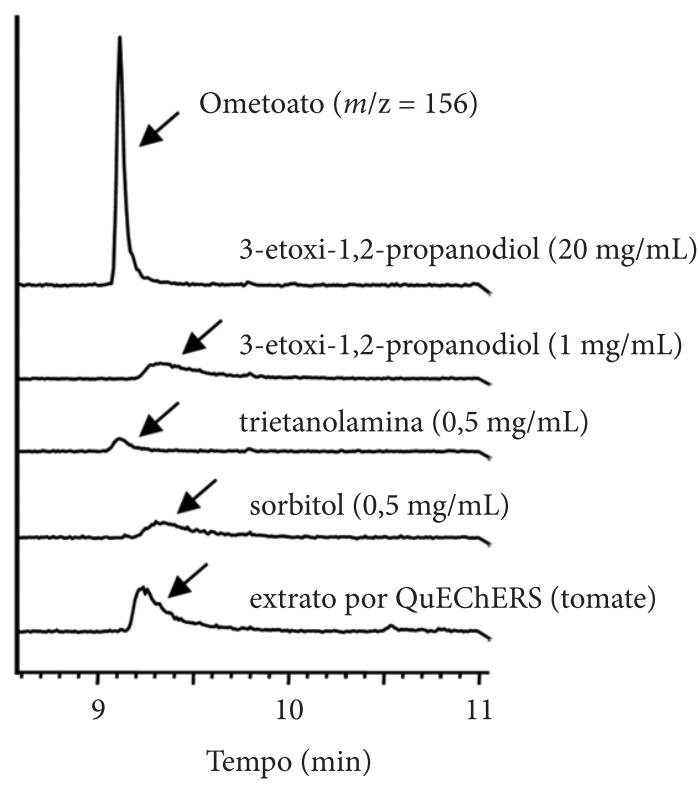

Figura 4 Efeito de diferentes protetores de analito avaliados sobre o formato do pico e intensidade de resposta de $1 \mu \mathrm{g} / \mathrm{mL}$ de ometoato por GC-MS. Com permissão, a partir da referência 8 . a abordagem mais interessante para ajuste das concentrações seria uma otimização multivariada.

Um dos aspectos mais interessantes do uso dos protetores de analito trata-se da capacidade desses compostos em tornar mais uniforme a resposta dos analitos injetados sob diferentes condições de matriz. Destaca-se que analitos diferentes podem sofrer maior ou menor influência da matriz, em relação às suas respostas em solvente puro (isento do efeito de matriz), todavia a escolha do protetor adequado tende a mitigar essa diferença entre matriz e solvente puro e, até mesmo, entre diferentes matrizes. A Figura 6 apresenta esse efeito para três analitos. $\mathrm{O}$ (a) lindano apresenta menos diferença na comparação à esquerda, por sofrer menor influência da diferença entre matriz e solvente puro; ainda assim a diferença de apenas $12 \%$ na intensidade é reduzida com o uso de um protetor (direita). O (b)

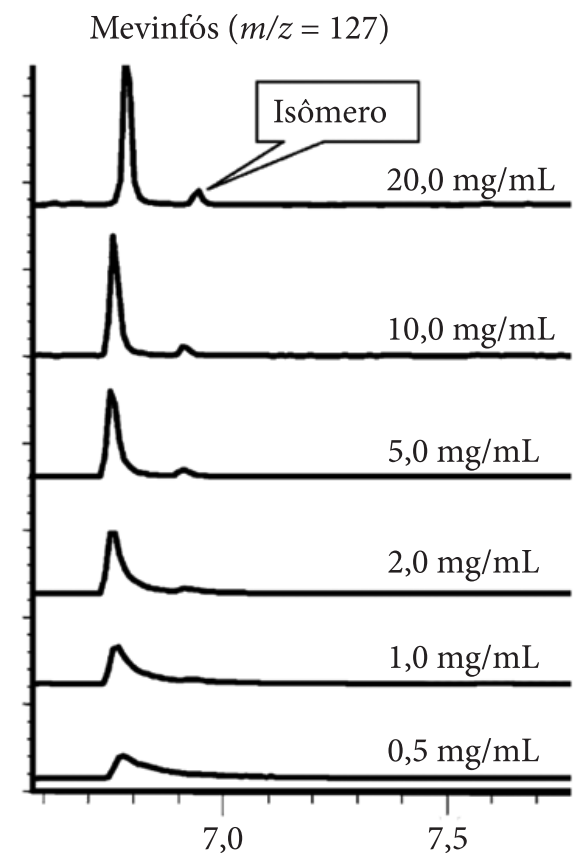

Figura 5 Influência da concentração do agente 3-etóxi-1,2-propanodiol sobre o formato do pico e intensidade de resposta de 0,25 $\mu \mathrm{g} / \mathrm{mL}$ de mevinfós por GC-MS. Com permissão, a partir da referência 8. 
fosalone apresenta grande aumento de resposta induzida pela matriz (esquerda), sendo a diferença totalmente corrigida pelos protetores utilizados (direita). Mais interessante é o caso do (c) o-fenilfenol, o qual apresenta grande diferença entre as respostas na ausência e presença de protetor, mesmo para a análise feita em matriz. Esse resultado indica que mesmo as análises realizadas fortificando-se a matriz podem ser melhoradas com os protetores de analitos, inclusive corrigindo-se eventuais diferenças entre as matrizes de amostras distintas. Ademais, verifica-se que uma diferença maior do que dez vezes entre matriz e solvente foi corrigida com o uso dos protetores apropriados.

Com relação ao aspecto quantitativo, a melhoria da exatidão pode ser inferida a partir da Figura 7. A resposta relativa de diferentes ana- litos em matriz e em solvente (matriz/solvente) é comparada entre extratos adicionados ou não de um protetor de analito. Observa-se que alguns analitos não são muito afetados, enquanto outros permitem a redução de um efeito de matriz "infinito", até valores aceitáveis.

A melhora quantitativa também se observa na precisão dos resultados. A Figura 8 permite a comparação da precisão, por meio do desvio padrão relativo calculado para a área, altura, razão altura/área e tempo de retenção dos picos de três analitos. Observa-se que a medida mais afetada pela ausência dos protetores de analito foi a altura do pico, justamente pela mudança no perfil do pico cromatográfico provocada pelas análises subsequentes, em que, gradativamente, uma maior carga de matriz foi sendo carregada no cromatógrafo. Contudo, sob a presença dos

A - Sem protetores de analito

B - Cem protetores de analito
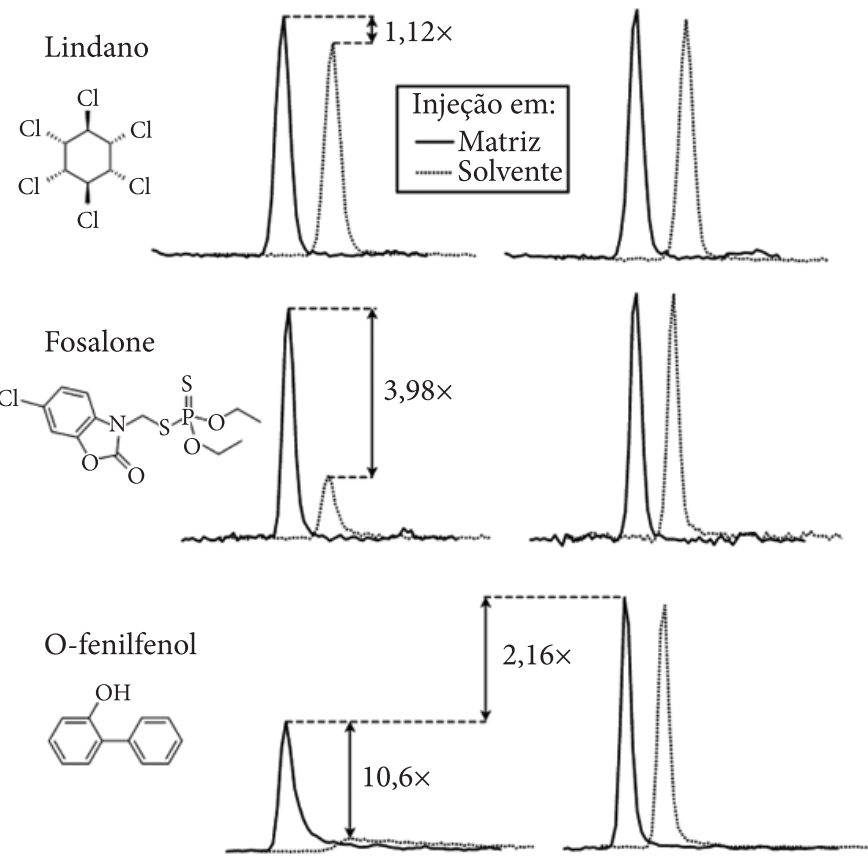

Figura 6 Comparação do formato dos picos e intensidades de resposta de $100 \mathrm{ng} / \mathrm{mL}$ de lindano $(\mathrm{m} / \mathrm{z} 219)$, fosalone (m/z 182) e o-fenilfenol ( $\mathrm{m} / \mathrm{z}$ 170) obtidos por injeções de soluções em matriz (extrato de fruta) e em solvente (acetonitrila), (A) sem e (B) com a adição de protetores de analitos (etilglicerol, gulonolactona e sorbitol; 10, 1 e $1 \mathrm{mg} / \mathrm{mL}$, respectivamente). Os números indicam o fator de aumento da resposta (altura do pico). Com permissão, a partir da referência 12 . 


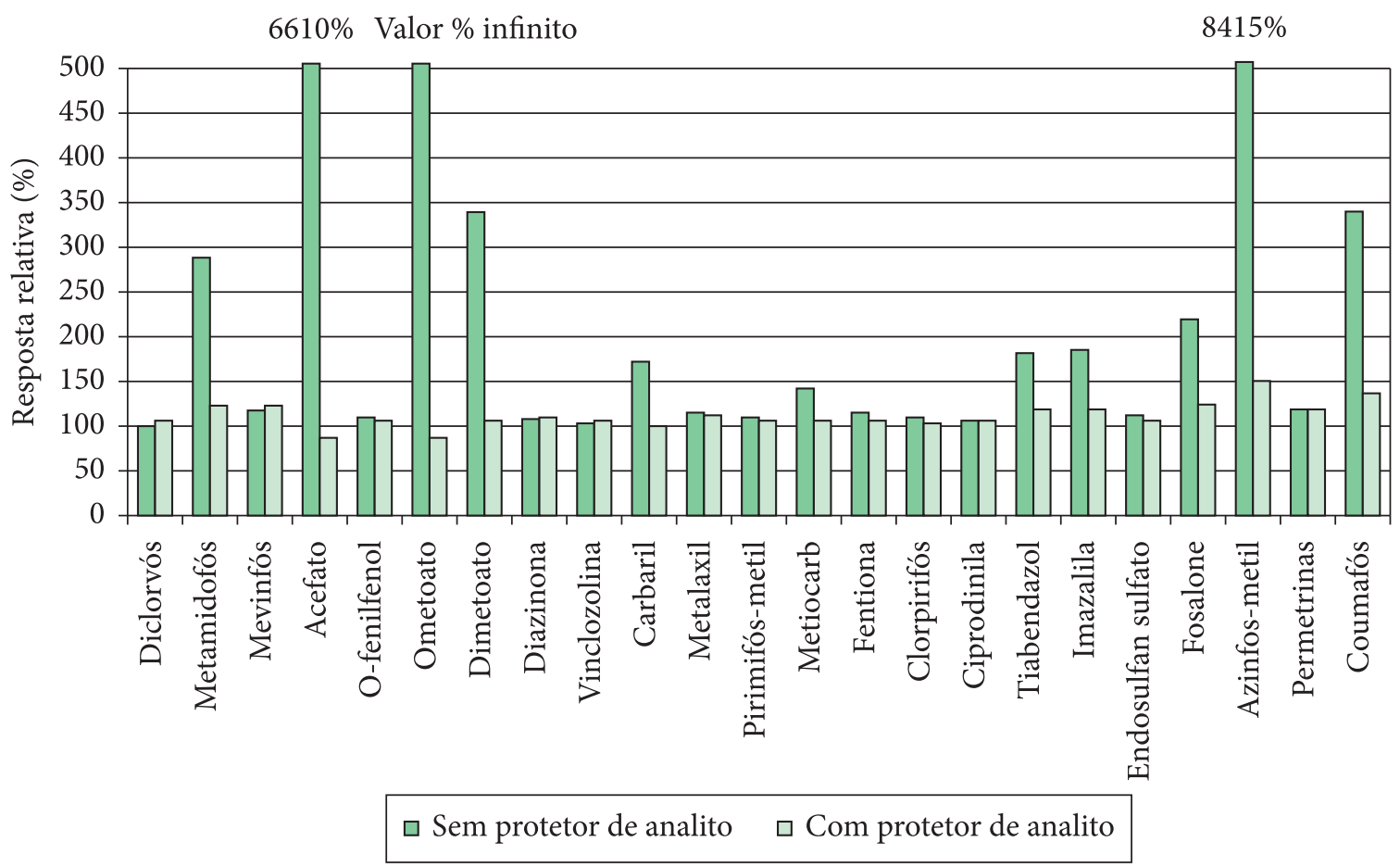

Figura 7 Comparação das respostas relativas de praguicidas selecionados a $0,5 \mu \mathrm{g} / \mathrm{mL}$ obtidos (A) sem e (B) com $0,5 \mathrm{mg} / \mathrm{mL}$ de gulonolactona adicionada como protetor de analito. As respostas relativas foram determinadas a partir da relação: (A) área do pico do padrão com compatibilização em matriz pêssego/área do pico do padrão em solvente $\times 100 \%$ e $(B)$ área do pico em matriz + protetor de analito/área do pico em solvente com protetor de analito $\times 100 \%$. Um valor de resposta relativa $100 \%$ é tido como correto e valores $>100 \%$ são superestimações devidas à indução ao aumento da resposta pelo efeito de matriz. Com permissão, a partir da referência 8.

protetores de analitos, a dispersão das respostas em todos os parâmetros foi trazida para valores aceitáveis.

Outra forma para se avaliar os resultados é apresentada na Figura 9. Nesse caso, curvas analíticas podem ser preparadas em solvente e em matriz, com e sem a adição dos protetores de analitos. Na Figura 9, admite-se um intervalo de tolerância de $15 \%$ para a resposta, ao redor das curvas obtidas em solvente. Dessa forma, observa-se por essa simulação que, sob a presença de protetores de analito, a curva em matriz não difere exageradamente daquela em solvente. Por outro lado, para o caso das curvas na ausência de protetores, foi feita simulação de tal maneira que a curva preparada em matriz apresentasse respostas relativas acima da tolerância estabelecida em 15\%. Em casos de analitos susceptíveis ao efeito de matriz em GC, e escolhendo-se protetores adequados para esses analitos, situações próximas à ilustrada na Figura 9 devem ocorrer. O posicionamento da curva em matriz e na ausência dos analitos (cor laranja), obviamente, vai depender da limpeza dessa matriz promovida pelo preparo de amostras e das características do analito em questão, podendo estar mais próxima das curvas com os protetores (região acinzentada), quando o efeito de matriz for mais alto, ou entre as duas curvas preparadas em solvente, quando o efeito de matriz sozinho não for comparável ao efeito produzido pelos protetores de analitos. 
A - Sem progetores de analito

Lindano

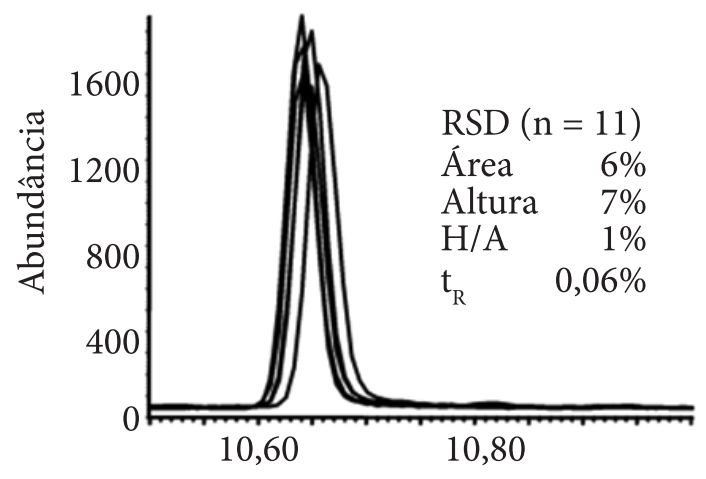

Fosalone

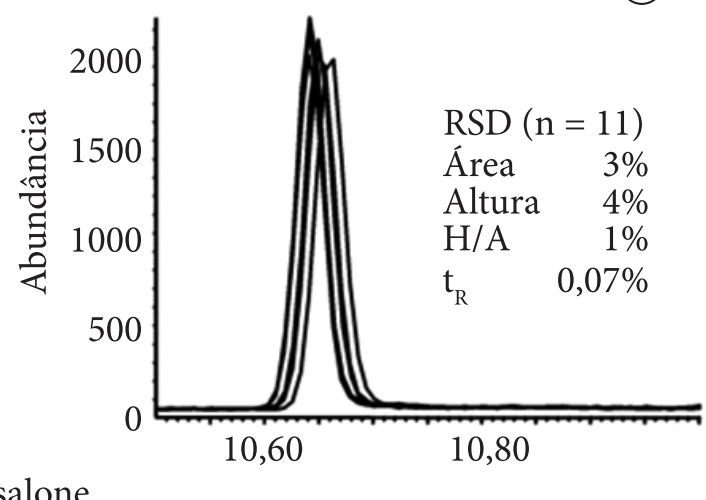

(b)
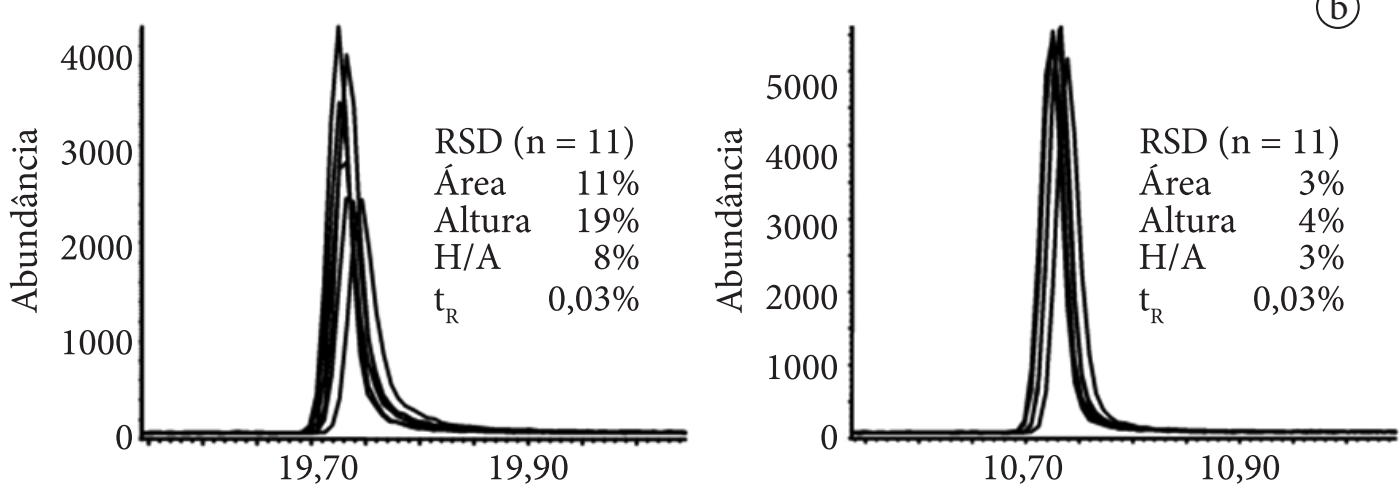

O-fenilfenol

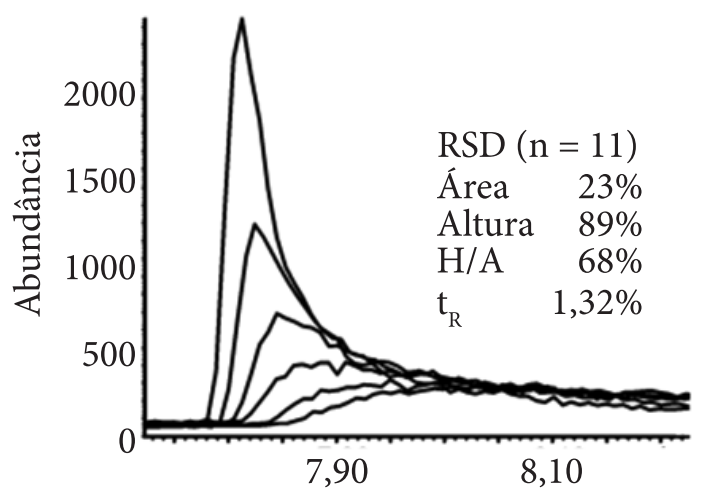

Minutos

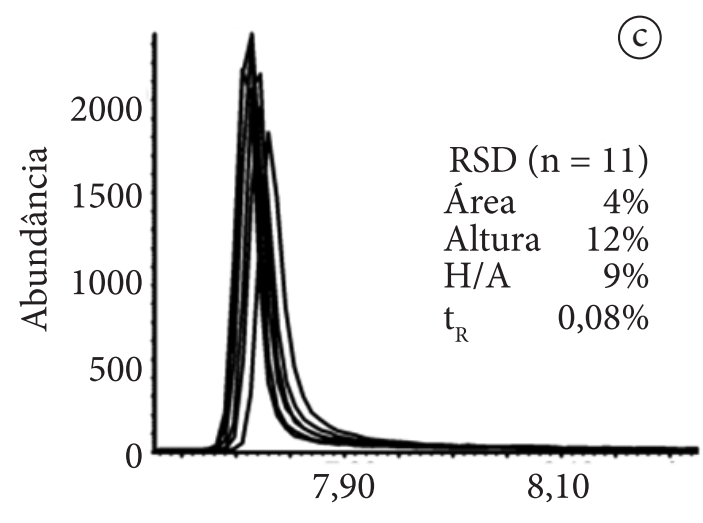

Minutos

Figura 8 Sobreposição dos picos cromatográficos de lindano ( $\mathrm{m} / \mathrm{z} 219)$, fosalone $(\mathrm{m} / \mathrm{z} 182)$ e o-fenilfenol $(\mathrm{m} / \mathrm{z}$ 170) obtidos em análises de $500 \mathrm{ng} / \mathrm{mL}$ dos padrões em acetonitrila (A) sem e (B) com a adição dos protetores de analitos (etilglicerol, gulonolactona e sorbitol; 10, 1 e $1 \mathrm{mg} / \mathrm{mL}$, respectivamente), ao início e após cada sequência de injeção de amostras (início, após 30, 60, 90, 120 e 150 injeções). O desvio padrão relativo (RSD) das áreas, alturas e razões altura/área $(H / A)$ dos picos e seus tempos de retenção $\left(t_{R}\right)$ são relacionados a injeções dos padrões em acetonitrila sem e com os protetores de analitos, sequencialmente $(n=11)$. Com permissão, a partir da referência 12 . 


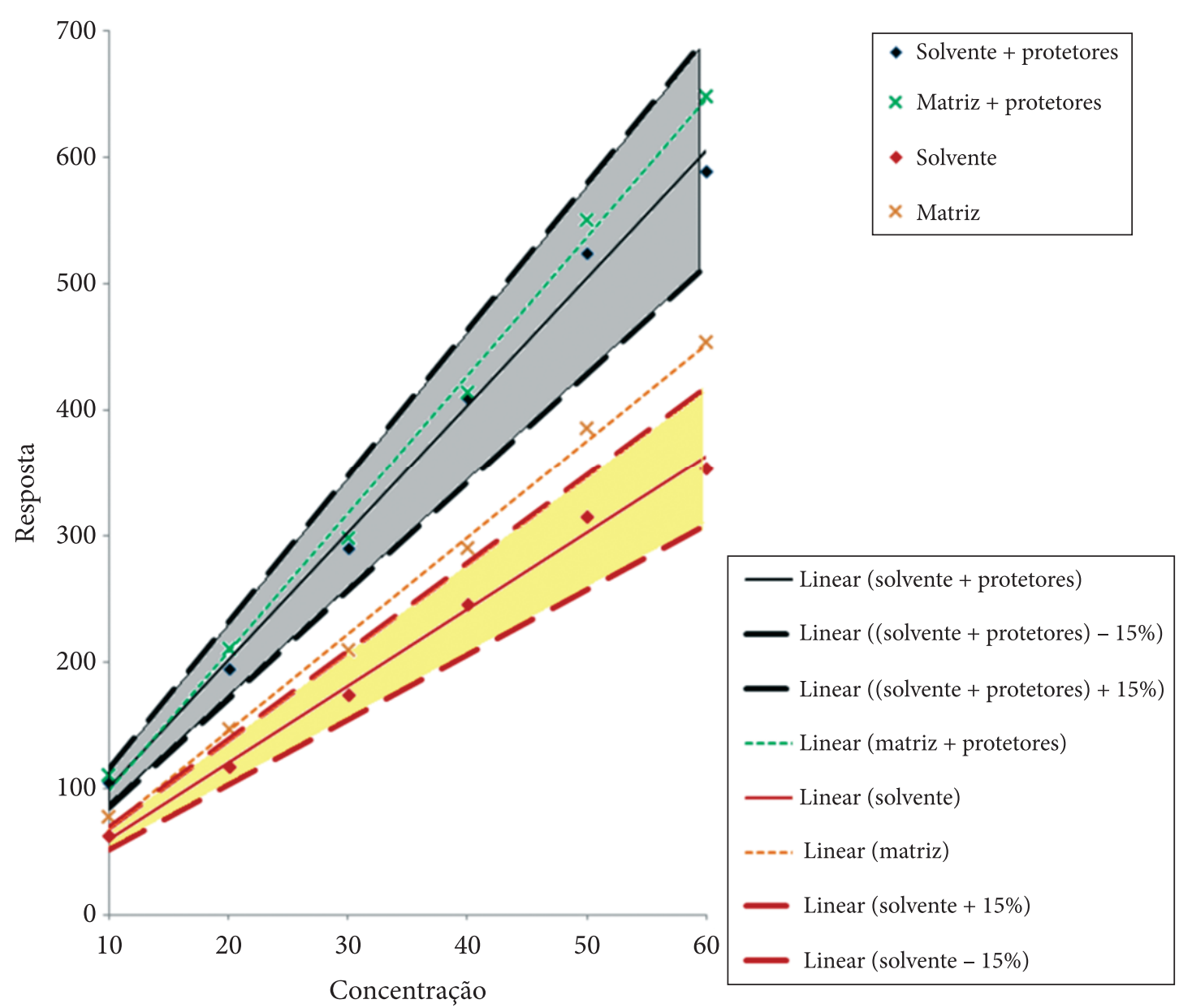

Figura 9 Curvas analíticas simulando a influência do efeito de matriz e dos protetores de analitos na quantificação. As retas ajustadas em verde e preto comparam uma curva obtida em matriz com outra em solvente, ambas sob efeito dos protetores de analitos. As retas ajustadas em vermelho e laranja são referentes aos analitos em matriz e em solvente, respectivamente, e sem a adição de protetores de analitos. As linhas grossas tracejadas em preto e vermelho delimitam uma região de mais ou menos $15 \%$ ao redor das retas ajustadas para os analitos em solvente (com e sem os protetores, regiões cinza e amarela, respectivamente). Observa-se que a reta em verde não se diferencia daquela em preto, além dos $15 \%$, enquanto a reta em laranja ultrapassa essa diferença em relação àquela de cor vermelha.

\section{Considerações finais}

Atualmente estudos de efeito de matriz são preconizados em muitos protocolos. Idealmente, tais estudos devem ser realizados todas as vezes que se suspeite que uma matriz complexa possa exercer tal efeito sobre os analitos em questão. Particularmente para GC, diversos praguicidas e também outras classes de compostos sofrem com o efeito de matriz que induz a maiores respostas, em relação aos mesmos padrões em soluções preparadas em solvente. Esse caso é muito evidenciado em matrizes de alimentos, mas pode ser extrapolado para outras matrizes complexas.

Independentemente da escolha quanto à forma de calibração, ao preparo das amostras $e$ às demais alternativas para mitigar o efeito de matriz, o uso de protetores de analitos vem ganhando atenção e demonstrando, inúmeras vezes, melhores resultados após a sua aplicação. Em suma, as vantagens do uso desses proteto- 
res são: (1) melhoria da intensidade e perfil dos picos cromatográficos; (2) uma boa limpeza dos extratos promovida pelo preparo da amostra não causa perdas na intensidade dos picos (devido à remoção do efeito indutor da matriz); (3) a identificação e integração dos picos tornam-se mais fáceis e exatas; (4) maiores seletividades, menores limites de detecção, e maior confiança nos resultados são obtidos; (5) diferentes protocolos de calibração podem ser adotados; (6) a abordagem é fácil, rápida e barata; (7) a manutenção do sistema para limpezas é reduzida (porque mesmo um sistema sujo com a matriz pode manter os resultados estáveis e confiáveis).

A melhor situação para uma análise seria a inexistência do efeito de matriz e a presença de analitos termicamente estáveis, voláteis e inertes com relação às interações indesejadas no sistema de GC. Uma situação dessas dispensaria a consideração para o uso de protetores de analitos. Em uma visão crítica, apesar de necessários e benéficos, os protetores de analitos são deixam de ser uma carga a mais de compostos a atravessar todo o sistema cromatográfico. Como o uso desses agentes costuma ser mais explorado quando a detecção é baseada na espectrometria de massas, um cuidado adicional pode ser recomendado. As concentrações relativamente mais altas dos protetores, fatalmente, chegam até a fonte de ionização do espectrômetro, onde o filamento emissor de elétrons pode sofrer maior desgaste ao tentar ionizar tudo aquilo que chega até essa região. Dessa forma, alguns equipamentos permitem que esse filamento seja desligado, nos intervalos do cromatograma em que nenhum composto de interesse tenha que ser detectado (evitando-se a saturação da ionização). O uso dessa opção pode ser uma forma de prolongar a vida útil do filamento, devendo ser considerada e discutida com os técnicos de manutenção especializados no instrumento de que se dispõe no laboratório.

\section{Agradecimentos}

À CAPES pela bolsa de mestrado concedida. Às agências de fomento FAPESP, CNPq e FAPEMIG.

\section{Referências}

1 Frache R, Mazzucotelli A. Determination of trace amounts of barium in silicate rocks and minerals by ion-exchange. Chromatography and atomic-absorption spectrophotometry. Talanta 1976; 23(5):389-91. http://dx.doi. org/10.1016/0039-9140(76)80053-7

2 Asmus PA, Low CE, Novotny M. Preparation and chromatographic evaluation of chemically bonded ion-exchange stationary phases. I. Strong anion-exchanger. Journal of Chromatography A 1976; 119(C):25-32. http://dx.doi.org/10.1016/ S0021-9673(00)86767-9

3 TaylorPJ.Matrixeffects:The Achillesheel of quantitative high-performance liquid chromatographyelectrospray-tandem mass spectrometry. Clinical Biochemistry 2005; 38(4):328-34. http://dx.doi. org/10.1016/j.clinbiochem.2004.11.007

4 Souverain S, Rudaz S, Veuthey JL. Matrix effect in LC-ESI-MS and LC-APCI-MS with off-line and on-line extraction procedures. Journal of Chromatography A 2004; 1058(1-2):61-6. http://dx.doi.org/10.1016/j. chroma.2004.08.118

5 Van De Steene JC, Lambert WE. Comparison of Matrix Effects in HPLC-MS/MS and UPLC-MS/ MS Analysis of Nine Basic Pharmaceuticals in Surface Waters. Journal of the American Society for Mass Spectrometry 2008; 19(5):713-8. http://dx.doi. org/10.1016/j.jasms.2008.01.013

6 Pinho GP, Neves AA, Queiroz MELR, Silvério FO. Efeito de matriz na quantificação de agrotóxicos por cromatografia gasosa. Quimica Nova 2009; 32(4):987-95. http://dx.doi.org/10.1590/ S0100-40422009000400030

7 Erney DR, Gillespie AM, Gilvydis DM, Poole CF. Explanation of the matrix-induced chromatographic response enhancement of organophosphorus pesticides during open tubular column gas chromatography with spitless or hot on-column injection and flame photometric detection. Journal of Chromatography 1993; 638(1):57-63. http://dx.doi. org/10.1016/0021-9673(93)85007-T 
8 Anastassiades M, Mastovská K, Lehotay SJ. Evaluation of analyte protectants to improve gas chromatographic analysis of pesticides. Journal of Chromatography A 2003; 1015(1-2):163-84. http://dx.doi.org/10.1016/ S0021-9673(03)01208-1

9 Cuadros-Rodríguez L, Gámiz-Gracia L, AlmansaLópez EM, Bosque-Sendra JM. Calibration in chemical measurement processes. II. A methodological approach. TrAC - Trends in Analytical Chemistry 2001; 20(11):620-36. http://dx.doi. org/10.1016/S0165-9936(01)00111-X

10 Erney DR, Poole CF. A study of single compound additives to minimize the matrix induced chromatographic response enhancement observed in the gas chromatography of pesticide residues. Journal of High Resolution Chromatography 1993; 16(8):501-3. http://dx.doi.org/10.1002/jhrc.1240160812
11 Anastassiades M, Lehotay SJ, Stajnbaher D, Schenck FJ. Fast and easy multiresidue method employing acetonitrile extraction/partitioning and "dispersive solid-phase extraction" for the determination of pesticide residues in produce. Journal of $A O A C$ International 2003; 86(2):412-31. PMid:12723926.

12 Mastovská K, Lehotay SJ, Anastassiades M. Combination of Analyte Protectants To Overcome Matrix Effects in Routine GC Analysis of Pesticide Residues in Food Matrixes. Analytical Chemistry 2005; 77(24):8129-37. http://dx.doi. org/10.1021/ac0515576

13 Soares LCT. Desenvolvimento de metodologia para quantificação de praguicidas organofosforados em café por GC-MS e estudo da degradação durante a etapa de torra [dissertação]. Alfenas: Universidade Federal de Alfenas; 2012. 84 p. 